\title{
Centro Acadêmico Rocha Lima
}

\author{
Gustavo Gregorin Coelho ${ }^{1}$ \& Sany Rose Bevervanso Ferrarese ${ }^{2}$ \\ 148. Turma. ${ }^{2} 47^{\text {a. }}$ Turma. Faculdade de Medicina de Ribeirão Preto - USP
}

"Todos passam

Ficaste sempre.

Solidificado pelo tempo,

Permaneceste firme.

Como o teu nome, és Rocha."

\section{INTRODUÇAO}

$\mathrm{N}$

o início de 1952, fora fundada a Facul dade de Medicina de Ribeirão Preto, da Universidade de São Paulo. Cerca de um mês após o início das aulas da primeira turma, alguns alunos passaram a se mobilizar para fundar uma entidade que reunisse e defendesse os interesses dos alunos. Após discussões e conversas, inclusive com o diretor e fundador da faculdade, professor Zeferino Vaz, foi realizada uma assembléia geral. Era dia 10 de junho de 1952, e estava sendo fundado o CENTRO ACADÊMICO ROCHA LIMA - CARL, entidade que representaria os alunos da FMRP-USP frente à sociedade. O CARL é constituído por todos os alunos da FMRP-USP e é um órgão independente da mesma instituição, sem fins lucrativos. Estatutariamente, seus fins são: defender, elevar o nome da FMRPUSP; defender os interesses de seus associados, no que for de direito e justiça; promover e incentivar atividades que possam contribuir para o desenvolvimento científico, ético, intelectual, artístico, político e social de seus associados; tornar agradável e educativo o convívio entre os associados e os demais CAs; promover conferências e reuniões sobre assuntos de interesse à comunidade acadêmica; prestar, quando possível, assistência econômica e social aos associados; promover e participar de campanhas para melhoria das condições médicas, sanitárias e educativas de nosso povo; zelar pelo bom entendimento entre corpo discente, corpo docente e diretoria da FMRP-USP; manter uma sede que proporcione espaço para as atividades do CA e conforto a seus associados; comemorar fatos e homenagear personalidades.

\section{O PATRONO}

Na mesma assembléia geral em que o Centro Acadêmico foi fundado, aprovou-se o nome do professor doutor Henrique da Rocha Lima como patrono. Existem duas versões para o fato: a primeira diz que o nome Rocha Lima fora uma sugestão do diretor Zeferino Vaz, pelo fato de ser ele uma pessoa de grande renome na época.A segunda versão explica que, na verdade, Rocha Lima foi uma imposição de Zeferino Vaz (Uma outra lenda diz que o fundador da faculdade agia como um verdadeiro ditador em muitos fatos relacionados à nova faculdade).

Lendas à parte, Henrique da Rocha Lima formou-se pela Faculdade de Medicina do Rio de Janeiro, nos primeiros anos do século 20. Foi colega, em pesquisas, de Carlos Chagas, Adolpho Lutz e Oswaldo Cruz. Trabalhou em Manguinhos, foi convidado a assumir o cargo de Assistente-Chefe de Anatomia Patológica da Universidade de Munique, ocupou o cargo de assistente no Instituto de Moléstias Tropicais em Hamburgo, foi subdiretor do Instituto Biológico em São Paulo. Além disso, participou da fundação da Escola Paulista de Medicina e da Universidade de São Paulo.Seus maiores prêmios e homenagens foram a Cruz de Ferro (maior condecoração alemã, conferida pessoalmente pelo imperador da Alemanha), a medalha de benemerência do papa Pio XI, a medalha Nocht (do Instituto de Doenças Tropicais de Hamburgo), e o título de membro efetivo da Academia Alemã de Ciências Naturais.Henrique da Rocha Lima, 
descobridor da Riquetsia prowazeck, morreu em 12 de abril de 1956, época em que era presidente da Sociedade Brasileira para o Progresso da Ciência e do Museu de Ciência.

\section{O BRASÃO}

O brasão do CARL é um escudo em forma de ogiva, forma que indica que se trata de uma faculdade latino-americana. No terço superior da ogiva, está o bastão em fundo verde, com uma cobra enrolada em sentido levógiro; nos dois terços inferiores, há uma tarja, que representa Ribeirão Preto. Além do brasão, o CARL também é representado por um logotipo. Trata-se da estilização de um bastão verde com uma cobra azul enrolada. Qualquer um dos dois simboliza a participação do CARL no evento ou situação.

\section{A SEDE}

O CARL já esteve instalado em inúmeras sedes. A primeira delas foi na república Mocolândia, no centro da cidade. A primeira sede oficial do CARL foi em três salas alugadas em um prédio à rua General Osório, número 331.Entre outros locais, merece destaque um casarão que ficava na rua Visconde de Inhaúma, número 757, ao lado da Catedral. Foi sede de momentos marcantes na vida dos acadêmicos da época (alguns desses "momentos" eram as festas dançantes de domingo). Quando o casarão foi vendido pelo proprietário, o CARL mudou-se para outro casarão, na mesma rua, número 1070 , perto da praça Camões. Foram as principais sedes até a década de 70. No início da década de 80, com a inauguração do novo HC, o CARL transferiu-se para o Campus. O novo ponto de encontro dos alunos passou a ser a antiga casa de força do Prédio Central, o famoso Galinheiro (já tinha sido realmente um galinheiro). Lá, o CARL passou toda a década de 80 e mais da metade da de 90. Com o crescimento e estruturação cada vez maiores, o CARL passou a necessitar de mais espaço para suas atividades, já que o número de ligas e de pessoas envolvidas com o CARL aumentava a todo momento. Assim, na gestão 1992/93, surgiu a idéia de expandir a sede do CARL(o Galinheiro). A expansão ocorreria em direção ao Prédio Central. Na gestão seguinte(93/94), foi elaborado um projeto por um engenheiro, porém, o terreno foi considerado fraco para suportar o projeto, além do fato de que a ampliação impediria uma expansão futura do Anexo A e do La- boratório Multidisciplinar. Assim sendo, na gestão 94/ 95, desistiu-se da ampliação e chegou-se ao consenso de que o CARL precisava de um novo prédio. A diretoria da Faculdade de Medicina apoiou a idéia e a área escolhida foi na mesma rua, ao lado da creche do Campus. Entretanto, um problema de localização ocorreu: nessa época, foram colocadas cancelas nos estacionamentos da faculdade e restaram poucas vagas para os estudantes. O CARL interveio, pedindo por um estacionamento exclusivo para os estudantes e o pedido foi acatado. Porém, o novo estacionamento e a área pré-determinada para a nova sede ficavam muito distantes entre si. Dessa forma, na gestão 95/ 96, estabeleceu-se que a nova sede seria construída ao lado do estacionamento dos alunos. A diretoria pagaria parte dos custos e o resto ficaria por conta do FUNDUSP. É nesse momento que surge uma grande confusão. A FUNDUSP não poderia doar o dinheiro diretamente ao CARL, pois este é uma entidade independente, sem vínculos estatutários com a USP. Por isso, seria construído um prédio para a faculdade, e a diretoria passaria a administração ao CARL; somente nessa situação a USP aprovaria o projeto. Após todos os anos de projeto e muitos problemas com burocracia e dinheiro, finalmente a nova sede seria construída, sob o nome de Centro de Vivências e administrada pelo CARL. Devido aos 45 anos de história de lutas dos alunos pelo engrandecimento da nossa honrosa FMRP-USP, e que procuramos reviver neste texto, é que o prédio atual é chamado, carinhosamente, por seus membros mais próximos de CA. Nessa mesma época, a Associação Atlética Acadêmica Rocha Lima (AAARL), tendo sua sede longe do acesso aos alunos, entrou em acordo para utilizar a sala em que haveria o xérox do CARL para montar uma sala de troféus e poder vender seus produtos e ter maior facilidade para arrecadar fundos. A construção do novo CARL iniciou-se em agosto de 1996. Em 07 de março de 1997, durante a gestão 96/97, foi descerrada a placa de inauguração do novo CARL. As obras só terminariam em agosto. No dia 05 daquele mês, finalmente o CARL estava pronto e era entregue aos alunos. As gestões seguintes (97/98 e 98/99) passaram a pensar em melhorias para o novo prédio. Essas melhorias ocorreram durante as gestões 99/2000 e 2000/2001, quando foram construídos quiosques , reformado o piso da área do ButeCARL e colocados bancos dentro do pequeno bosque ao lado do CARL. Os alunos da FMRP-USP possuem, hoje, um belíssimo Centro Acadêmico, reconhecido por todos que o co- 
nhecem como um espaço ímpar para a realização de atividades do movimento estudantil, mantendo à disposição dos alunos uma biblioteca (recentemente ampliada pela doação de livros pela fundação PHAECIA), sala de estar, salas de reunião, ar condicionado, área de jogos(a área do ButeCARL), sala de arquivos e restaurante. Como está escrito na placa de inauguração do novo CARL: "Esta obra exprime a plena integração de cinco Diretorias Executivas do Centro Acadêmico Rocha Lima, que cooperaram em sua ideação, projeto, consecução, soerguimento e término, oferecendo-nos exemplo ideal de trabalho continuado". A esse texto apenas acrescenta-se que, hoje, já se somam mais quatro gestões de Diretorias Executivas na manutenção dessa grande obra, o prédio-sede do CARL.

\section{AS DIVISÕES}

O CARL tem seus trabalhos divididos entre uma diretoria executiva, departamentos, coordenadorias e ligas. Nesses 50 anos de história, departamentos, coordenadorias e ligas nasceram e desapareceram. Citaremos os desaparecidos, e depois, detalharemos os que estão em atividade.

\section{PASSADO}

No passado, o CARL possuiu o Departamentos Social, o de Propaganda, o de Assistência e Previdência, o Feminino e o de Esportes, além da Liga Brasileira de Combate à Moléstia de Chagas. Com o tempo, perderam função e desapareceram. Os registros sobre esses departamentos são mínimos. Sabe-se que o Departamento Social era responsável por eventos de integração entre os alunos, como festas e bailes. Com o passar dos anos, uniu-se ao Departamento Cultural da época, que pouco fazia (apenas mantinha uma biblioteca), e formaram um novo departamento, o Cultural, do qual falaremos mais à frente. O Departamento de Propaganda tinha como função avisar os alunos dos fatos e eventos que iriam ocorrer, ou seja, fazer propaganda. O Departamento de Assistência e Previdência tinha uma função interessante: mantinha uma farmácia e fazia empréstimos financeiros aos sócios necessitados, além de vender livros a preço de custo aos alunos da faculdade. $\mathrm{O}$ caso mais intrigante é o do Departamento Feminino. Sabe-se apenas que só podiam participar mulheres e todos os anos havia um jantar entre veteranas e calouras. Já o Departa- mento de Esportes promoveu alguns eventos esportivos e, em 1954, desapareceu, surgindo a AAARL, com uma diretoria própria, eleita pelos sócios do CARL. Anos depois, emancipou-se completamente, criando uma nova entidade. Em relação à Liga Brasileira de Combate à Moléstia de Chagas, sabe-se que teve muitos anos de atividade, principalmente nos primórdios da FMRP-USP, nas décadas de 50 e 60. Fazia campanhas de prevenção com a população, palestras com os estudantes e estudos sobre a doença e seu vetor biológico. Essa liga foi de grande importância em sua época, pelo fato de a região de Ribeirão Preto ser área endêmica da doença.

\section{DEPARTAMENTOS}

Departamento Científico: em 50 anos, esse Departamento já elaborou dezenas de cursos, palestras, simpósios e congressos para complementar a formação dos alunos de Medicina. Sempre foi um Departamento muito forte dentro do CARL, possuindo muitos participantes e dinheiro. Ajudou o Campus Ribeirão a ser reconhecido nacionalmente, como importante centro de pesquisa, afinal, era responsável por todos os estágios que os alunos faziam com docentes da FMRP-USP. Apesar de todas as realizações acima, a vedete do Departamento CIENTÍFICO é o Congresso Médico Acadêmico (COMA), que apresenta trabalhos científicos de estudantes de Medicina de várias faculdades do Brasil. No COMA, é entregue o Prêmio Rocha Lima ao melhor trabalho científico feito e apresentado por alunos. O Departamento Científico publicou algumas edições de uma revista científica em conjunto com o CAOC (Centro Acadêmico Oswaldo Cruz, da FMUSP). Além de tudo isso, outra contribuição, a maior, do Departamento Científico merece um capítulo especial: a revista MEDICINA, na qual este tex to está sendo publicado hoje.

Departamento Cultural: como escrito acima, existiu um Departamento Cultural e um Social, que se uniram e formaram o atual Departamento Cultural. No início da FMRP-USP, eram famosos o Baile Branco, que sucumbiu com o tempo e a perda do glamour, e o Show Medicina (realizado entre 1955 e 1963). Era um evento requintado, sendo que as apresentações aconteciam no Teatro Pedro II. Os ingressos acabavam uma semana antes do evento. As autoridades e pessoas de renome da cidade compareciam ao espetáculo (prefeito, vereadores, etc). Porém, veio a ditadura, e o espetáculo parou por trinta anos. O Show 
Medicina voltaria a ser realizado em 1993, com o nome de Show Med e a cada ano se torna um evento mais interessante. O Departamento Cultural também realizou o Jah por dois anos e prepara todo ano a mais animada Festa Junina do Campus. Na década de 90, o Baile Branco foi reativado, sendo um sucesso, porém sem lucro. Devido a isso, no ano seguinte, 1993, passou-se a realizar o macabro Baile Preto, outro grande sucesso, no estacionamento do CARL, com direito a bandas e decoração obscura. Outro evento produzido pelo Departamento Cultural é o CineCARL, ocorrendo exibição de filmes com discussão após o término. No entanto, a mais famosa realização do Departamento Cultural é o ButeCARL (esclarecendo: buteco + CARL = ButeCARL). Como diz o ditado, toda quinta-feira tem ButeCARL. A partir das 18 $\mathrm{h}$, acontece famoso happy hour em que os alunos e até alguns professores se encontram para tomar cerveja, comer cachorro quente, jogar uma partida de truco e passar horas contando histórias do passado. Enfim, o Departamento Cultural é o responsável pelos momentos de festa e distração dos acadêmicos.

Departamento de Imprensa: responsável por divulgar informações, opiniões, idéias e fomentar discussões entre os alunos. O Departamento de Imprensa confecciona aquele que é considerado um dos melhores jornais universitários do país, o ESTETO. O nome foi escolhido em assembléia geral do CARL e, inicialmente chamava-se O ESTETO. Apenas na década de 90 passou a chamar-se ESTETO. A primeira edição foi publicada no dia 21 de outubro de 1953. A partir de 1955, O ESTETO passa a ser suplemento do jornal O DIÁRIO DE NOTÍCIAS (seria suplemento desse jornal até a década de 70). Na década de 50, a linguagem utilizada era muito formal e predominavam textos informativos do CARL, sobre a Liga de Chagas, sobre os departamentos, existiam as páginas literária e a científica, além de comentários sobre o Baile Branco e o Show Medicina, eventos de grande prestígio na cidade. Um dos grandes colaboradores de $\mathrm{O}$ ESTETO foi o diretor Zeferino Vaz. Na década de 60, mantém-se a linha da década anterior, até 1967 , quando ocorre uma mudança no papel, tamanho e capa, alterando toda sua aparência. A década de 70 traz mudanças radicais. Há menos exemplares, O ESTETO deixa de ser suplemento de O DIÁRIO DE NOTÍCIAS, é mimeografado, desaparecem as citações ao Baile Branco, as páginas literária e científica. No lugar, surgem artigos sobre censura, política, repressão, movimento estudantil e quadrinhos com críticas soci- ais. A década de 80 causa certa estranheza, já que existem poucas edições nos arquivos. Das edições que restam, algumas mantêm a linha da década anterior. Aparentemente, foi um período de baixa no Departamento de Imprensa. Porém, na década de 90, o departamento reergue-se. O ESTETO passa a chamarse ESTETO e passa a ter um modelo fixo, com seções constantes e textos relativos aos acontecimentos ocorridos no CARL. Em 1997, surgiu o prêmio ESTETO de OURO, entregue durante o Show Med, aos escritores dos melhores textos publicados no ESTETO no período entre dois Shows Med. Nos primeiros anos do novo milênio, o ESTETO continua seguindo os padrões dos anos 90 , esperando 21 de outubro de 2003, data em que comemorará seus 50 anos.

Departamento de Ensino - "Não há educação mais revolucionária do que aquela que ensina a considerar o mundo não como uma realidade já feita, inexorável, mas como uma obra a ser criada" Garaudy

É conhecido como a "coluna vertebral" do CARL, é um departamento de extrema importância, pois promove discussões sobre o ensino médico, assim como sugere e tenta implantar modificações necessárias. Promove assembléias, reuniões e fóruns de discussão sobre assuntos relevantes ao ensino médico e à prática médica. Uma das principais funções é possibilitar a reunião e integração dos representantes discentes (RD) em um fórum único de troca de experiências e informações. É importante lembrar que, em muitas outras unidades da USP, não há um espaço como esse em que os alunos possam estar trabalhando juntos, e não só o $\mathrm{RD}$, em prol da excelência que pretendemos manter para continuar sempre como uma das, senão a melhor Faculdade de Medicina do País. O Departamento de Ensino atua a todo momento, e isso dificulta muito escrever sobre seus feitos, pois esses resultados não aparecem de imediato, devido à burocracia da faculdade pública, já que é necessário muito tempo até que uma conquista do departamento seja colocada em prática. É sempre importante ressaltar que o ensino não deve ser algo estático, ele deve procurar a dinamicidade, para envolver o aluno no desenvolver de um raciocínio crítico que lhe proporcione, em qualquer lugar a qualquer momento, avaliar o que se propõe como um novo e moderno conhecimento. O Departamento de Ensino preza-se por essas qualidades, quando faz alguma proposta para um departamento ou para outros colegiados a que a discussão seja pertinente. 


\section{A REVISTA MEDICINA}

Em 1959, alunos, membros do Departamento Científico, procuraram o professor Maurício da Rocha e Silva com a intenção de serem orientados por ele, na publicação de uma revista científica. Após muita dedicação e dificuldade, surge, em 1961, o primeiro número de MEDICINA, revista do Centro Acadêmico Rocha Lima. Assim, os alunos da FMRP-USP passaram a ter uma forma de publicar suas pesquisas científicas. Vale destacar que a revista MEDICINA foi a primeira publicação do gênero, ocorrida no interior do estado de São Paulo e, talvez, do interior do Brasil. Com o passar dos anos, a revista MEDICINA cresceu e passou a ser produzida em conjunto com o Hospital das Clínicas da FMRP-USP. Nessa época, já recebia trabalhos, para publicação, de docentes, além dos próprios alunos. A revista cresceu tanto que o CARL deixou de participar de sua confecção, passando sua total administração ao Hospital das Clínicas. Hoje, a revista MEDICINA é extremamente conceituada no meio médico.

\section{LIGAS}

Liga de Assistência Médico Social (LAMS): a mais antiga liga do CARL, em funcionamento, foi fundada em 1957, com a "finalidade de despertar e desenvolver, entre os universitários, o espírito de medicina social e assistir médica e socialmente a população, na medida de suas limitações como entidade universitária e segundo análise de seus membros, prestando e aceitando para tanto a colaboração de entidades afins", segundo consta em seu estatuto. A LAMS trabalha em três frentes distintas (Puericultura, Geriatria e Saúde Reprodutiva). A frente de Puericultura aborda a prevenção na saúde biopsicossocial de crianças de 0 a 02 anos e na melhoria do desenvolvimento na infância. A frente de Geriatria enfoca o ensino e prevenção para uma melhor qualidade de vida do idoso e a busca por um envelhecimento sadio. Por fim, a frente de Saúde Reprodutiva focaliza a saúde da mulher em idade reprodutiva, tanto na sexualidade quanto na gravidez.

Liga de Combate à Hanseníase, LUIZ MARINO BECHELLI: fundada em 22 de outubro de 1991, seu nome é uma homenagem a um médico dedicado ao assunto. Essa liga realiza importante trabalho curativo e preventivo contra a hanseníase, através de atendimentos ambulatoriais, visitas domiciliares, sessões de poliquimioterapia, biópsias de pele, palestras na comunidade, seminários para os alunos, congressos, jornadas e simpósios sobre a doença.

Liga de Combate à AIDS e DSTs: atua nas frentes assistencial e preventiva, através de atendimento ambulatorial aos pacientes portadores do vírus HIV e com doenças sexualmente transmissíveis, além de atividades educativas como palestras, distribuição de preservativos e panfletos, apoio psicológico e jornadas sobre AIDS E DSTs.

Liga do Trauma: iniciou seus trabalhos em novembro de 1995, após um grupo de alunos tomarem conhecimento da assustadora quantidade de mortes ocorridas devido a traumas. O objetivo era combater o problema através de discussões, campanhas preventivas, palestras, atendimento ambulatorial e reabilitação às vítimas. Em 2001, a liga organizou o COLT (Congresso das Ligas do Trauma), com participação de ligas de várias faculdades. Vinculado à Liga do Trauma, temos o Núcleo de Primeiros Socorros. Esse núcleo oferece cursos sobre primeiros socorros, semestralmente. Os cursos se dividem em duas partes: o curso básico e, após a participação nesse, o curso avançado.

Liga de Combate ao Câncer: surgiu em novembro de 1996, com a finalidade de prestar assistência à população, esclarecendo sobre as formas de câncer, fazendo campanhas de prevenção, acompanhando a evolução de pacientes oncológicos. Ainda realiza seminários baseados em casos clínicos e jornadas oncológicas, para maior conhecimento dos alunos sobre o assunto.

Liga de Diabetes: fundada na década de 90, tem como objetivo propiciar aos alunos uma melhor formação para oferecer palestras a escolas, fábricas e instituições e também atendimento e campanhas de esclarecimento à população. Os alunos aprendem as técnicas de atendimento através de aulas práticas e teóricas, oferecidas por professores e membros mais antigos da liga.

Liga de Hipertensão Arterial (LHA): fundada em 03 de setembro de 1986, pertencendo ao Centro Médico de Ribeirão Preto, não contava com a participação de alunos. Em 1996, alunos da FMRP-USP e da EERP (Escola de Enfermagem) passam a participar dos atendimentos ambulatoriais. Em 1999, a LHA desvincula-se do Centro Médico e filia-se ao CARL. Entre suas atividades estão o atendimento, atividade preventiva, tentativa de diagnóstico precoce e organização de eventos de divulgação e atualização sobre a hipertensão arterial.

Liga Pró-Transplante: surgiu no início de 1999, com o intuito de criar campanhas de doação de ór- 
gãos, distribuir panfletos de esclarecimento sobre as doações e sobre os transplantes de órgãos, atuar junto às equipes de captação de órgãos, preparar palestras e seminários relacionados a transplantes e projetos sociais de apoio aos pacientes transplantados.

Liga de Saúde Mental: iniciou seus trabalhos na segunda metade de 1999, objetivando combater o preconceito em relação à doença mental, ajudar na manutenção da saúde mental da população e ampliar a formação acadêmica em relação ao assunto.

\section{DIRETORIA EXECUTIVA}

Formada por um grupo de alunos que, anualmente, são eleitos para administrar o CARL. Por muitos é tido como o CARL, mas essa é uma idéia errônea, visto que o CARL é formado por todos os departamentos e ligas associadas, sendo apenas centralizadas pela Diretoria Executiva. Na realidade, é a parte burocrática e que responde legalmente pelo Centro Acadêmico Rocha Lima, além de ser a responsável administrativa pela sede, estacionamento dos alunos e praça. Além disso, tem como outra função promover a congregação dos diversos departamentos e ligas e o intercâmbio de informações entre todos os membros sejam eles participantes ativos ou não das atividades do CARL. Para isso é que, a cada 15 dias, ocorre a publicação do PICA (Periódico Informativo do Centro Acadêmico) e as informações são colocadas nos murais do CARL (na sede e no HC). Há de se convir que é um trabalho ingrato, pois depende do interesse alheio pelo que está ocorrendo à sua volta. Para procurar agilizar um pouco seu trabalho, divide-se em coordenadorias:

Coordenadoria de Informática: responsável pela manutenção dos computadores, impressoras e scanner, assim como pela Home Page do CARL (www.fmrp.usp.br/carl), em funcionamento e devidamente atualizados.

Coordenadoria de Marketing: tem como função a confecção do PICA, além de espalhar o nome CARL entre os alunos através de seus produtos (mochilas, bolsas, adesivos, pastas, chaveiros, pochetes, pastas-mala, estojos).

Coordenadoria de Ligas: através de reuniões entre as diretorias das ligas e representantes da Diretoria Executiva e atuando junto à faculdade, procura resolver os problemas referentes a cada liga do CARL.

Coordenadoria de Relações Internacionais (CRI): atua de forma a disponibilizar intercâmbios entre os alunos da FMRP-USP e alunos de outras Fa- culdades de Medicina do mundo. A CRI ainda objetiva viabilizar projetos de saúde pública em países subdesenvolvidos.

Coordenadoria de Extensão: criada recentemente para fazer trabalhos com a comunidade, visando a uma melhoria na qualidade de vida da população, através de trabalho educativo e não assistencialista, e também do aprendizado e da conscientização social dos alunos da FMRP-USP.

Coordenadoria de Relações Externas (RelEx): zela pela comunicação e troca de experiências do CARL com os outros CAs de Medicina de todo o país, assim como com os demais CAs de toda a USP. Sua atividade se dá através de reuniões periódicas com os outros CAs de São Paulo e Paraná (Regional Sul 2), e dos encontros realizados pela DENEM (Direção Executiva Nacional dos Estudantes de Medicina), entidade que congrega todos os CAs e DAs de Medicina do Brasil. Os encontros podem ser regionais (Encontro Regional dos Estudantes de Medicina - Regional Sul 2) ou Nacionais ( Encontro Científico dos Estudantes de Medicina, Congresso Brasileiro dos Estudantes de Medicina). A função do COBREM é a de traçar as diretrizes do movimento estudantil no decorrer do ano, além de promover discussões de temas relacionados ao ensino e às políticas de saúde; a intenção do ECEM é o momento de manifestações culturais, científicas, artísticas e políticas dos estudantes de Medicina do país. E, finalmente, o EREM, que é um encontro mais restrito, por ser regional e onde pode haver uma maior integração, discussão e troca de experiências entre os CAs e com as atividades promovidas pela DENEM. Não há registros da participação do CARL em atividades da DENEM antes de 1992. No ano de 2001, o CARL sediou o EREM da Regional Sul-2, proporcionando, assim, aos alunos da FMRP-USP uma maior aproximação com as discussões que estão sendo realizadas no meio acadêmico.

\section{CONSIDERAÇÕES FINAIS}

Terminamos esse texto, ressaltando a importância do CARL na manutenção e aprimoramento da Faculdade de Medicina de Ribeirão Preto. O CARL possui uma participação acadêmica altíssima, somando-se departamentos, ligas e diretoria executiva. Não há nenhuma entidade estudantil no país com tamanha abrangência. Através de pessoas, em sua maioria anônimas, o CARL contribuiu de forma contundente para o atual cenário da FMRP-USP. Foram essas pessoas anônimas que subiram em mesas dentro do CARL, 
para impedir que o governo militar as levasse. Essas pessoas estiveram presentes em milhares de reuniões, muitas feitas com luz apagada e janelas fechadas, para não despertar a atenção da repressão. Pessoas que ocuparam por duas semanas a Superintendência do Hospital das Clínicas, lutando contra a imposição de regras prejudiciais no acesso à Residência Médica. Mais que isso, doaram parte de seu tempo com o intuito de ajudar as próximas gerações de alunos a receberem um melhor ensino, e, acima de tudo, fizeram com que o CARL pudesse ajudar a transformar e manter a Faculdade de Medicina de Ribeirão Preto da Universidade de São Paulo, como uma das maiores, senão a maior, Faculdade de Medicina do Brasil.

\section{AGRADECIMENTOS}

A todos os que um dia dedicaram parte de seu tempo ao CARL, e ajudaram a construir esses 50 anos de história e glória os agradecimentos do Centro Acadêmico Rocha Lima.

\section{BIBLIOGRAFIA CONSULTADA}

1 - CENTRO ACADÊMICO ROCHA LIMA. Estatuto do Centro Acadêmico Rocha Lima da Faculdade de Medicina de Ribeirão Preto da Universidade de São Paulo. Ribeirão Preto, 1996.

2 - CENTRO ACADÊMICO ROCHA LIMA. ESTETO especial-45 anos. Ribeirão Preto, s.d.

3 - CENTRO ACADÊMICO ROCHA LIMA. Departamento de Imprensa. ESTETO. Ribeirão Preto, s.d.

4 - CENTRO ACADÊMICO ROCHA LIMA. Manual do calouro do CARL. Ribeirão Preto, 1999.

5 - CENTRO ACADÊMICO ROCHA LIMA. Manual do calouro do CARL. Ribeirão Preto, 2001.

6 - DALMAZZO LFF. Movimento estudantil de Medicina. Vedas 2:43-45, 1998.

7 - ZUARDI AW; GARCIA SB \& ALBUQUERQUE LMM. A evolução de um movimento: Entrevista. Vedas 2:17-20, 2000. 